\title{
O COMPROMISSO DO PROFISSIONAL EM FORMAÇÃO COM A SOCIEDADE: RELATO DE EXPERIÊNCIA INTENSIVA E MULTIDISCIPLINAR DE EXTENSÃO UNIVERSITÁRIA
}

\author{
Juliana Campregher PASQUALINI ${ }^{1}$ \\ Fernando Ramalho MARTINS ${ }^{2}$ \\ Roberto Carlos MIGUEL ${ }^{3}$
}

Resumo: Esse artigo relata uma experiência de extensão multidisciplinar intensiva em um município de pequeno porte no Estado do Mato Grosso realizada em julho de 2015 por um grupo de dois professores e oito alunos da UNESP (Universidade Estadual Paulista) que participaram de uma Operação do Projeto Rondon. A equipe foi formada por docentes e alunos dos cursos de Administração Pública, Ciências Biológicas, Farmácia, Pedagogia, Psicologia e Serviço Social. Relataremos aqui o processo de preparação, planejamento e execução das ações da equipe, destacando os principais resultados, as dificuldades enfrentadas, a contribuição para a formação discente e aspectos que, em nossa análise, se mostraram fundamentais para a consecução dos objetivos: o processo grupal e a eleição das políticas sociais e garantia de direitos como articuladores fundamentais da intervenção.

Palavras-chave: Extensão universitária. Formação profissional. Processo grupal. Políticas sociais. Projeto Rondon.

\section{Introdução}

Esse artigo relata uma experiência de extensão multidisciplinar intensiva em um município de pequeno porte no Estado do Mato Grosso realizada em julho de 2015 por um grupo de dois professores e oito alunos da UNESP (Universidade Estadual Paulista) que participaram de uma Operação do Projeto Rondon. Após uma contextualização inicial do Projeto Rondon, acompanhada de reflexões sobre seus objetivos e sentido social, faremos uma breve caracterização do município em que foram realizadas as ações e em seguida relataremos a experiência de intervenção, abordando desde a seleção da equipe de trabalho até as principais dificuldades enfrentadas e resultados alcançados, buscando edificar, a partir desse relato, conclusões e indicações referentes às possíveis

${ }^{1}$ UNESP - Universidade Estadual Paulista "Júlio de Mesquita Filho". Faculdade de Ciências de Bauru Departamento de Psicologia. Bauru - SP - Brasil. 17033-360 - jupasqualini@uol.com.br

2 UNESP - Universidade Estadual Paulista "Júlio de Mesquita Filho". Faculdade de Ciências e Letras Departamento de Administração Pública. Araraquara - SP - Brasil. 14800-901 fernandomartins@fclar.unesp.br

${ }^{3}$ UNESP - Universidade Estadual Paulista “Júlio de Mesquita Filho". Faculdade de Ciências e Letras Departamento de Psicologia da Educação. Araraquara - SP - Brasil. 14800-901 - roberto@ fclar.unesp.br 
contribuições que a participação em um projeto de extensão universitária nos moldes proporcionados pelo Projeto Rondon pode trazer à formação no ensino superior. Destacaremos na análise a importância do processo grupal em um contexto de intervenção multidisciplinar na realidade, bem como condições promotoras do compromisso do profissional com a sociedade.

O Projeto Rondon foi criado em 1967 e permaneceu em vigência até o ano de 1989. Em 2005, foi reativado pelo Governo Federal, a partir de proposta encaminhada à presidência da República em novembro de 2003 pela União Nacional dos Estudantes (UNE). Em sua versão atual, a coordenação do Projeto é de responsabilidade do Ministério da Defesa (em colaboração com outros ministérios), cabendo às Forças Armadas a logística das Operações. Às Instituições de Ensino Superior cabe a apresentação de propostas de trabalho nos eixos "Cultura, Direitos Humanos e Justiça, Educação e Saúde" (Conjunto A) ou "Comunicação, Tecnologia e Produção, Meio Ambiente e Trabalho" (Conjunto B). As propostas são submetidas a uma comissão que seleciona as mais bem avaliadas. Em cada município que recebe a Operação são alocadas simultaneamente duas equipes oriundas de duas diferentes universidades, responsáveis respectivamente por cada um desses eixos.

No artigo "Em 2005, o velho Projeto Rondon”, a antropóloga Ruth Cardoso tece críticas à reativação do programa, explicitando algumas das contradições presentes em sua origem e histórico. De acordo com a autora, o Projeto foi "uma das marcas registradas da ditadura militar", desenvolvido sem o apoio das universidades e dirigido por militares, atuando como estratégia para "afastar os estudantes das manifestações de oposição [...]" (CARDOSO, 2005, p.A2). Ainda que o texto mencionado oriente-se pela oposição entre Projeto Rondon e Universidade Solidária (UniSol) - com claro posicionamento em favor do último, o qual foi iniciado em 1995 na gestão Fernando Henrique Cardoso, à qual a autora se vinculava na condição de primeira-dama - os apontamentos realizados por Ruth Cardoso destacam de forma pertinente contradições inerentes ao Projeto, não plenamente superadas em sua nova roupagem e organização.

Consideramos, portanto, que o legado de sua gênese fatalmente deixa marcas no significado social do Projeto, ao mesmo tempo em que avaliamos que, nas novas circunstâncias histórico-sociais, em particular com a consolidação do regime democrático de Direito no país e refluxo dos movimentos populares contestatórios, o sentido político-ideológico do Projeto Rondon altera-se em relação ao denunciado por Ruth Cardoso no contexto do Regime Militar. Tendo em vista registrar nossas reflexões, 
compreensão e posicionamento diante dessas questões - de modo a situar o sentido e os propósitos que nos orientaram no curso da intervenção aqui relatada - é preciso, inicialmente, considerar os objetivos formalmente declarados do Projeto Rondon em sua vigência atual.

De acordo com a Portaria Normativa n. 2.617 (BRASIL, 2015a), o Projeto Rondon tem como objetivos gerais "contribuir para o desenvolvimento e o fortalecimento da cidadania do estudante universitário" e "contribuir com o desenvolvimento sustentável, o bem-estar social e a qualidade de vida nas comunidades carentes, usando as habilidades universitárias". Como objetivos específicos, o que se anuncia como pretendido é "proporcionar ao estudante universitário conhecimento de aspectos peculiares da realidade brasileira", "contribuir com o fortalecimento das políticas públicas, atendendo às necessidades específicas das comunidades selecionadas", "desenvolver no estudante universitário sentimentos de responsabilidade social, espírito crítico e patriotismo", e "contribuir para o intercâmbio de conhecimentos entre as instituições de ensino superior, governos locais e lideranças comunitárias".

Assim, o Projeto orienta-se - segundo seus propositores ${ }^{4}$ - pela perspectiva de contribuir para a formação do universitário como cidadão; integrar o universitário ao processo de desenvolvimento nacional, por meio de ações participativas sobre a realidade do País; consolidar no universitário brasileiro o sentido de responsabilidade social, coletiva, em prol da cidadania, do desenvolvimento e da defesa dos interesses nacionais; e estimular no universitário a produção de projetos coletivos locais, em parceria com as comunidades assistidas. Nota-se, assim, que a formação do universitário na perspectiva da "cidadania" e da "defesa dos interesses nacionais" é colocada como foco principal, ao mesmo tempo em que se atingem, por meio das Operações, municípios com baixos índices de desenvolvimento econômico e social.

Fica evidente que o Projeto continua a atender a interesses governamentais no sentido da "integração nacional", na medida em que constitui um meio de o Estado fazer-se presente de modo pontual e temporário em regiões pauperizadas do país, valendo-se de uma concepção focalizada de "políticas sociais" (em detrimento de uma visão universalista) ${ }^{5}$. Nesse contexto, a perspectiva de atendimento a comunidades

\footnotetext{
${ }^{4}$ Disponível em: <http://projetorondon.pagina-oficial.com/portal/index/pagina/id/9752/area/C/module/ default $>$. Acesso em: 30 jun. 2016.

${ }^{5}$ De acordo com Senhoras (2003, p.13) a focalização das Políticas Sociais é um dos indicativos da adesão à agenda neoliberal, implementada no país durante a década de 1990. Destarte, é possível observar a adesão do Estado ao "reinado do minimalismo" ou das "pequenas soluções ad hoc", tendo como
} 
"carentes" é concretizada "usando" as habilidades universitárias. Além disso, consideramos nítida a intencionalidade de difusão e fortalecimento de um (temerário) sentimento patriótico, reverberando uma (problemática) ideologia nacionalista, propiciando um contato do estudante universitário que pode ser caracterizado, em certo sentido, como promoção (ou mesmo propaganda) das Forças Armadas, veiculando uma imagem positiva do Exército (no caso da Operação em questão) como "força de paz" que contribui para o desenvolvimento de ações socialmente relevantes para o progresso do país em regiões longínquas, de acesso impraticável às iniciativas de extensão universitária.

Por outro lado, é preciso destacar que o Projeto Rondon garante hoje aos docentes plena autonomia na proposição das ações a serem realizadas nos municípios alcançados pelas Operações, em todas as suas dimensões: público-alvo, objetivos, conteúdo e estratégias ${ }^{6}$. Ademais, a coordenação do grupo de estudantes, desde a seleção dos alunos até a conclusão das ações no município, é também realizada com autonomia pelos docentes: em nossa experiência, não sofremos nenhum tipo de interferência além das normas gerais previamente estabelecidas pela Coordenação do Projeto que devem ser observadas por todos os assim chamados "rondonistas" (como, por exemplo, a proibição da ingestão de bebidas alcoólicas pelos estudantes durante o período da Operação, ou o uso do uniforme em todas as ações nos municípios vinculadas ao Projeto). A liberdade docente no planejamento e condução do trabalho da equipe é uma condição que abre a possibilidade de se proporcionar ao aluno uma experiência que se caracterize como extensão universitária e contribua para a formação crítica do futuro profissional.

Diante do exposto, posicionamo-nos no sentido de reconhecer que as contradições estão postas, mas há um conjunto de forças em ação cuja "resultante" determinará a quais interesses sociais e/ou políticos as ações efetivamente realizadas nos municípios servirão. No atual cenário político brasileiro, avaliamos que o principal desafio que se coloca à comunidade acadêmica que integra o Projeto Rondon é superar o ranço assistencialista ainda presente em grande parte das ações realizadas - traço esse

corolário: "o desmonte de Políticas Sociais existentes - sobretudo aquelas de âmbito nacional - sem deixar nada em substituição", bem como a transferência da responsabilidade destas para o âmbito municipal, sem o correspondente repasse de recursos.

${ }^{6}$ Destacamos, nesse sentido, a própria existência de editais anuais nos quais constam as exigências e critérios válidos para todos os interessados em apresentar propostas de intervenção nos municípios. Ainda que de modo limitado, a existência do edital pode ser compreendida como um instrumento burocrático que colabora para combater ranços patrimonialistas e clientelistas. 
não raro sustentado e reforçado pelos próprios docentes proponentes dos projetos de intervenção.

A participação no Projeto Rondon cria a possibilidade de se proporcionar ao estudante universitário o contato com a precariedade das condições de vida da população local (marcada pela violação sistemática de direitos fundamentais), o intercâmbio de conhecimentos com as comunidades e grupos populares, o acesso a instâncias do poder público municipal e uma genuína troca humana com os munícipes que participam das atividades propostas pelo projeto, além de uma experiência intensiva de grupalização ao longo das duas semanas de convivência e trabalho coletivo entre a equipe. Pretendemos demonstrar, nesse artigo, que a depender do direcionamento dado pela coordenação docente, essas condições podem contribuir para a implicação do estudante com os problemas sociais a partir da especificidade de sua área de formação e para o compromisso do profissional em formação com a sociedade em que vive.

Um último destaque antes de adentrarmos o relato e análise da intervenção propriamente dita se faz relevante. Desde que garantida a devida mediação pelos docentes, consideramos que também pode ter impacto relevante e positivo para a formação humana/crítica dos estudantes o contato com a realidade e as contradições do Exército. Identificamos pelo menos duas dimensões da experiência que abrem essa possibilidade: primeiramente, a imersão no cotidiano do quartel que recebe e concentra todas as equipes oriundas dos diversos Estados do país nos primeiros dias da Operação, anteriormente à ida para os municípios. A possibilidade de vivenciar - ainda que artificialmente, dada a condição de visitantes temporários - a rotina controlada, ritualizada e vigiada, marcada por regras que não podem ser questionadas e pelo princípio da impessoalidade, que ao mesmo tempo promove um senso de igualdade perante a regra, mas também o sentimento de invisibilidade e de perda da individualidade, revelou-se experiência impactante para nossos alunos e também para nós mesmos, na condição de coordenadores. A origem socioeconômica dos soldados e a disciplina militar que parece anular o sujeito ao mesmo tempo em que possibilita a consecução de objetivos somente atingíveis mediante coordenação altamente complexa de ações de muitos indivíduos são exemplos de aspectos da vida nessa instituição que contrastam de forma extrema com o ambiente universitário, que (idealmente) cultiva o questionamento, o pensamento crítico, a liberdade.

Em segundo lugar, mas não menos impactante, é a convivência que "humaniza" o militar aos olhos do universitário - no sentido de criar a possibilidade de percebê-lo 
como pessoa, para além da farda. Para acompanhar cada equipe no município em que desenvolverá a intervenção é designado um militar. Nos mais de quinze dias de convívio diuturno com o soldado que acompanhou nossa equipe ao município, isso pôde ser vivenciado de modo bastante intenso, concretizando-se como construção de uma relação marcada pelo respeito mútuo, diálogo e vínculo afetivo, a ponto de se expressar em espontâneas homenagens dos estudantes na cerimônia de encerramento e em discurso sobre a amizade proferido em meio a lágrimas pelo sargento no momento da despedida do grupo.

Feito esse preâmbulo, que busca situar os objetivos e o sentido social do Projeto Rondon, identificando suas contradições e em seu interior possibilidades de direcionamento da experiência para uma formação crítica e reflexiva do universitário, passaremos à caracterização do território e detalhamento da intervenção realizada.

\section{A realidade do município}

A Operação Bororos foi realizada em simultaneamente 15 municípios do Mato Grosso, no período de 10 a 24 de julho de 2015. Para contextualização do trabalho realizado, faremos uma breve caracterização do território em termos da paisagem geográfica e condições sócio-econômicas.

O Estado do Mato Grosso possui 142 municípios, distribuídos em 5 Mesorregiões e 22 Microrregiões. Estas regiões possuem uma rica biodiversidade: o bioma Amazônia ocupa a porção norte do estado, o Cerrado a porção central, e o Pantanal, no sul do Estado, é o bioma com menor representação em área. Sua grande extensão territorial $\left(903.357 \mathrm{~km}^{2}\right)$ lhe confere uma grande diversidade de tipos climáticos. O clima do Estado varia de acordo com a posição geográfica, mas o clima predominante é o tropical superúmido, tipicamente amazônico, caracterizado por calor e umidade em abundância $\left(26^{\circ} \mathrm{C}\right.$ em média).

Em 2010, a população estimada desse Estado era de 3.035.122 habitantes, sendo $81,80 \%$ estabelecidas em áreas urbanas. A grande maioria desta população possui acesso à energia elétrica e água tratada. A região, desde a década de 1990, vem apresentando sinais de melhorias, haja vista o crescimento do seu Índice de Desenvolvimento Humano Municipal (IDHM), um dos principais indicadores nacionais utilizados para medir o desenvolvimento, que passou de 0,449 em 1991 para 0,725 em 2010. A melhoria desse índice pode ser explicada pela melhoria nas três dimensões 
avaliadas, a saber: longevidade, educação e rentabilidade. Na tabela abaixo é possível visualizar os dados que dão amparo à referida melhoria (ATLAS, 2013a).

Tabela 1 - Índice de Desenvolvimento Humano Municipal e seus componentes - Mato Grosso

\begin{tabular}{lrrr} 
IDHM e componentes & $\mathbf{1 9 9 1}$ & $\mathbf{2 0 0 0}$ & $\mathbf{2 0 1 0}$ \\
\hline IDHM Educaçäo & 0,221 & 0,426 & 0,635 \\
\% de 18 anos ou mais com ensino fundamental completo & 24,76 & 35,82 & 53,20 \\
\hline$\%$ de 5 a 6 anos frequentando a escola & 25,77 & 63,00 & 86,80 \\
\hline$\%$ de 11 a 13 anos frequentando os anos finais do ensino fundamental & 33,96 & 62,42 & 85,82 \\
\hline$\%$ de 15 a 17 anos com ensino fundamental completo & 15,68 & 37,66 & 62,17 \\
\hline \% de 18 a 20 anos com ensino médio completo & 8,36 & 22,53 & 42,36 \\
\hline IDHM Longevidade & 0,654 & 0,740 & 0,821 \\
\hline$\quad$ Esperança de vida ao nascer (em anos) & 64,24 & 69,38 & 74,25 \\
\hline IDHM Renda & 0,627 & 0,689 & 0,732 \\
\hline$\quad$ Renda per capita (em R\$) & 395,34 & 582,62 & 762,52
\end{tabular}

Fonte: Atlas (2013a).

No tocante à economia, o Estado destaca-se pela produção agrícola. Desde 2014, o Estado lidera o ranking nacional de produção agropecuária, ultrapassando inclusive o Estado de São Paulo. Suas lavouras e sua pecuária geraram 62,37 bilhões de reais no ano de 2015, ultrapassando aquele Estado em quase 1 bilhão de reais. Em 2015, 85\% do faturamento bruto do Mato Grosso adveio da produção de algodão, milho, soja e carne bovina (BRASIL, 2015b).

Quinze cidades foram selecionadas para recepcionar e compor a Operação Bororos. Nossa equipe foi alocada no município de Rosário Oeste, a $113 \mathrm{Km}$ da capital Cuiabá, com população de aproximadamente 17.679 habitantes, espalhados numa área de $7.516,25 \mathrm{~km}^{2}$.

A história do município remonta ao ano de 1750 com a chegada de seus primeiros moradores atraídos pelo ouro. Em 1861 o município foi fundado com o nome de Nossa Senhora do Rio Acima, sendo este nome substituído por Rosário Oeste no ano de 1915. A cidade está localizada na mesorregião Centro Sul Matogrossence (IBGE, 2015). A população está concentrada, em sua maioria, na área urbana da cidade, totalizando 60,26\%. Além disso, quando comparado com o ano de 1991, é possível perceber um afinamento da base da pirâmide etária da cidade e um discreto alargamento de seu topo, causados pela diminuição da população com idade inferior a 15 anos e pelo aumento da expectativa de vida.

No que tange à educação, considerando dados referentes ao ano de 2010, 37,89\% da população de 18 anos ou mais tinha completado o Ensino Fundamental e 23,92\% o Ensino Médio, enquanto no Mato Grosso esses índices eram de, 
respectivamente, $53,20 \%$ e $35,59 \%$. O número de analfabetos totalizava $21,2 \%$ da população, o que chama atenção por estar bastante acima da média nacional, bem como da média estadual (10,8\%). De modo similar, o número de habitantes com 25 anos ou mais que possuem ensino superior completo também se mostrou abaixo da média estadual. Em 2010, apenas 5,47\% dos munícipes se enquadravam nesta categoria, sendo que no Estado esse índice é de 10,47\% (ATLAS, 2013a, 2013b).

No quesito renda per capita, embora tenha apresentado melhoras em termos de comparação histórica, Rosário Oeste tem índice 39\% inferior ao do Estado. Também considerando dados referentes a 2010, a renda per capita no Mato Grosso foi estimada em 762,52 reais enquanto Rosário Oeste teve índice de 465,66 reais. Nesse mesmo ano, no conjunto do Estado $10,52 \%$ da população foi considerada pobre e 4,41\% extremamente pobre, ao passo que no município os índices correspondentes foram de 19,29\% (pobreza) e 7,75\% (pobreza extrema), alcançando pouco menos que o dobro da média Estadual (ATLAS, 2013a, 2013b). Ainda no que tange à renda, 81,89\% dos munícipes com idade igual ou superior a 18 anos recebia até dois salários mínimos, ao passo que no Estado esse número cai para 66,26\%. O grau de formalização dos ocupados também apresenta um percentual desfavorável em relação ao Estado. Em 2010, apenas $41 \%$ da população encontrava-se em condição formal de emprego (ATLAS, 2013a, 2013b).

Tais indicadores se refletem em outros indicadores sociais, como se pode notar comparando as tabelas 2 e 3 abaixo, onde são sintetizados dados relativos à vulnerabilidade social, que o município onde se deu a intervenção sempre apresenta índices abaixo da média estadual.

Tabela 2 - Vulnerabilidade Social - Município de Rosário Oeste.

\begin{tabular}{|c|c|c|c|}
\hline Crianças e Jovens & 1991 & 2000 & 2010 \\
\hline Mortalidade infantil & 34,09 & 26,30 & 17,90 \\
\hline$\%$ de crianças de 0 a 5 anos fora da escola & & 86,04 & 78,00 \\
\hline$\%$ de crianças de 6 a 14 fora da escola & 42,25 & 9,60 & 3,48 \\
\hline $\begin{array}{l}\text { \% de pessoas de } 15 \text { a } 24 \text { anos que nāo estudam, nāo trabalham e sāo vulneráveis, na populaçāo } \\
\text { dessa faixa }\end{array}$ & - & 21,06 & 11,99 \\
\hline$\%$ de mulheres de 10 a 17 anos que tiveram filhos & 1,65 & 3,97 & 2,72 \\
\hline Taxa de atividade - 10 a 14 anos & - & 11,70 & 15,27 \\
\hline \multicolumn{4}{|l|}{ Familia } \\
\hline $\begin{array}{l}\% \text { de mäes chefes de familia sem fundamental e com filho menor, no total de māes chefes de } \\
\text { familia }\end{array}$ & 14,75 & 23,45 & 23,92 \\
\hline$\%$ de vulneráveis e dependentes de idosos & 4,86 & 4,43 & 3,67 \\
\hline $\begin{array}{l}\% \text { de crianças com até } 14 \text { anos de idade que têm renda domiciliar per capita igual ou inferior a R\$ } \\
70,00 \text { mensais }\end{array}$ & 35,69 & 25,99 & 12,03 \\
\hline \multicolumn{4}{|l|}{ Trabalho e Renda } \\
\hline$\%$ de vulneráveis à pobreza & 78,85 & 68,78 & 42,09 \\
\hline$\%$ de pessoas de 18 anos ou mais sem fundamental completo e em ocupaçäo informal & - & 65,22 & 51,46 \\
\hline \multicolumn{4}{|l|}{ Condiçāo de Moradia } \\
\hline$\%$ da populaçāo em domicilios com banheiro e água encanada & 38,20 & 51,41 & 82,56 \\
\hline
\end{tabular}

Fonte: Atlas (2013b). 
Tabela 3 - Vulnerabilidade Social - Estado do Mato Grosso

\begin{tabular}{|c|c|c|c|}
\hline Crianças e Jovens & 1991 & 2000 & 2010 \\
\hline Mortalidade infantil & 33,64 & 27,53 & 16,80 \\
\hline$\%$ de crianças de 0 a 5 anos fora da escola & - & 84,46 & 63,78 \\
\hline$\%$ de crianças de 6 a 14 fora da escola & 27,28 & 8,17 & 3,76 \\
\hline $\begin{array}{l}\text { \% de pessoas de } 15 \text { a } 24 \text { anos que nào estudam, nào trabalham e sào vulneráveis, na populaçāo } \\
\text { dessa faixa }\end{array}$ & - & 14,58 & 8,69 \\
\hline$\%$ de mulheres de 10 a 17 anos que tiveram filhos & 3,62 & 4,47 & 3,30 \\
\hline Taxa de atividade - 10 a 14 anos & - & 10,56 & 8,99 \\
\hline \multicolumn{4}{|l|}{ Familia } \\
\hline $\begin{array}{l}\% \text { de màes chefes de familia sem fundamental e com filho menor, no total de mäes chefes de } \\
\text { familia }\end{array}$ & 13,09 & 13,62 & 15,68 \\
\hline$\%$ de vulneráveis e dependentes de idosos & 1,95 & 2,25 & 1,71 \\
\hline $\begin{array}{l}\% \text { de crianças com ate } 14 \text { anos de idade que têm renda domiciliar per capita igual ou inferior a RS } \\
70,00 \text { mensais }\end{array}$ & 18,58 & 11,39 & 6,84 \\
\hline \multicolumn{4}{|l|}{ Trabalho e Renda } \\
\hline$\%$ de vulneráveis à pobreza & 60,87 & 46,92 & 27,00 \\
\hline$\%$ de pessoas de 18 anos ou mais sem fundamental completo e em ocupaçào informal & $\cdot$ & 51,54 & 34,94 \\
\hline \multicolumn{4}{|l|}{ Condiçāo de Moradia } \\
\hline \% da populaçào em domicilios com banheiro e água encanada & 55,50 & 70,92 & 90,37 \\
\hline
\end{tabular}

Fonte: Atlas (2013a).

\section{Formação da equipe, planejamento das ações e preparação dos alunos}

A equipe foi formada por discentes dos cursos de graduação em Administração Pública, Ciências Biológicas, Farmácia, Pedagogia, Psicologia e Serviço Social; a coordenação ficou a cargo de dois docentes respectivamente vinculados aos Departamentos de Administração Pública (Faculdade de Ciências e Letras do campus Araraquara da UNESP) e de Psicologia (Faculdade de Ciências do campus Bauru da mesma universidade), que contaram com apoio de um colega docente do Departamento de Psicologia da Educação (campus Araraquara) com larga experiência de participação no Projeto Rondon no delineamento geral das ações a serem desenvolvidas.

Considerando o número limitado de vagas (oito estudantes), foi necessário realizar processo seletivo. Os candidatos foram solicitados a endereçar aos coordenadores carta de interesse e proposta de oficina abordando uma das temáticas que comporia a Operação. A partir dessa documentação, foram avaliadas as principais motivações explicitadas pelos candidatos, a capacidade de planejamento de intervenções (considerando clareza e pertinência de objetivos e estratégias, riqueza de conteúdos, adequação ao público-alvo e gerenciamento do tempo), bem como o alinhamento com a vertente teórico-política de trabalho dos coordenadores. Foi também considerada, na montagem da equipe, a importância de se garantir uma composição multidisciplinar, visando abranger as diversas subáreas do Conjunto A (Cultura, Direitos Humanos e 
Justiça, Educação e Saúde) e proporcionar interlocução e parcerias de trabalho entre universitários de áreas de formação diversas.

Para a elaboração inicial do plano de ações - que foi submetido ao Ministério da Defesa na fase de seleção de propostas - foi realizada análise socioeconômica dos municípios que participariam da Operação Bororos (conforme os dados acima apresentados), buscando mapear, a partir de dados secundários, as principais problemáticas socioeconômicas e psicossociais das realidades a serem atendidas pelo projeto, orientando, assim, a proposição das atividades de extensão que o grupo iria desenvolver.

Num segundo momento - já tendo a proposta sido selecionada para compor a Operação e tendo sido designado ao grupo pela Coordenação Geral o município de Rosário Oeste - foi realizada a viagem precursora, na qual o docente coordenador principal permaneceu durante uma semana no município visando avaliar junto aos membros do poder executivo municipal a adequação das atividades propostas em relação às demandas locais. Além disso, coube ao coordenador, nesse momento, verificar as condições de hospedagem e transporte oferecidos pela prefeitura local; levantar possíveis locais para realização das oficinas e palestras; e, por fim, discutir e projetar estratégias de divulgação prévia das atividades (ou seja, antes da chegada da equipe ao município). Importante destacar que também participou da viagem precursora o coordenador do Conjunto B. Assim, a partir da mencionada viagem, coordenadores e grupos puderam realizar um trabalho de lapidação das atividades anteriormente propostas, visando atender mais eficientemente às demandas e necessidades das comunidades em questão, considerando a totalidade das ações que seriam desenvolvidas na cidade.

Por fim, a terceira etapa do trabalho de preparação consistiu na organização do trabalho coletivo propriamente dita, envolvendo o (re)planejamento detalhado das ações, designação dos responsáveis pela execução de cada atividade e montagem do cronograma de ações. As atividades foram planejadas no formato de palestras e oficinas com duração média de 3 horas, detalhando-se objetivos, público-alvo, conteúdo, estratégias e recursos, tendo sido intensivamente discutidas pela equipe ao longo de três reuniões preparatórias, em período integral (com aproximadamente seis horas de duração cada). ${ }^{7}$

\footnotetext{
${ }^{7}$ Importante registrar que se fez vasto uso de ferramentas de comunicação a distância (incluindo um grupo no facebook) no período de preparação das atividades.
} 
As temáticas gerais norteadoras da intervenção foram: infância, etnia e gênero; condição feminina; educação sexual, diversidade e combate à discriminação; direitos do idoso; projeto de vida e projeto profissional do adolescente (orientação profissional); trabalho docente e projeto pedagógico na escola; literatura infantil; participação popular e cidadania; saúde comunitária e uso racional de medicação; abuso de substâncias psicoativas; divulgação e valorização da produção cinematográfica brasileira (mini-ciclo de cinema nacional); valorização da história e cultura local. O tema e o público-alvo das oficinas e palestras foram definidos considerando-se as demandas do município e, ao mesmo tempo, o repertório teórico-técnico e os interesses temáticos dos integrantes da equipe. Optou-se preferencialmente pelo trabalho em duplas, como estratégia para possibilitar e fomentar o intercâmbio de conhecimentos e a experiência de trabalho coletivo; nos casos em que um estudante ficava individualmente responsável pela preparação e coordenação de uma atividade, designava-se um colega que cumpriria a função de apoio, tendo em vista a alta probabilidade da ocorrência de imprevistos. Tendo sido definidas as oficinas a serem realizadas e os responsáveis por sua preparação e coordenação, os estudantes foram requisitados a elaborar um planejamento detalhado de cada atividade. As propostas foram discutidas nas reuniões coletivas, movimento que proporcionou que todos não apenas tomassem conhecimento do que seria realizado pelos demais integrantes da equipe, mas se implicassem com o conjunto das ações que comporia a Operação.

\section{A execução do planejado: a prática como critério de verdade}

Com a chegada da equipe ao município, iniciou-se a fase de execução das ações idealizadas. A primeira e principal dificuldade que se apresentou nas intervenções iniciais foi a baixa adesão da população local. Duas oficinas deixaram de ser realizadas por ausência de participantes. Rapidamente identificou-se que o trabalho de divulgação anterior à chegada do município que ficara a cargo dos gestores locais foi insuficiente (ou não realizado). Essa situação foi avaliada pelas duas equipes e definiu-se que todos deveriam engajar-se em um trabalho de divulgação e mobilização da população, por meio de caminhadas pelos bairros com distribuição de panfletos e convites, participação em programa da rádio local e visitas às Secretarias Municipais tendo em vista consolidar parcerias para a efetivação das ações. Nessa fase inicial, os discentes vivenciaram sentimento de frustração pela ausência de público nas atividades por eles cuidadosamente planejadas e preparadas e, em sentido mais amplo, pelo 
desconhecimento e baixo interesse da população pelas ações do Projeto. Ainda que esse cenário tenha prejudicado o alcance da intervenção nos momentos iniciais da Operação, ele revelou o insuficiente conhecimento da equipe a respeito da realidade local e possibilitou importantes aprendizados para o grupo a respeito da parceria com o poder público e demais agentes sociais, da obtenção do engajamento da população e do alcance possível de ações extensionistas, permitindo uma análise das necessidades e interesses impulsionadores (ou não) das ações dos diversos segmentos envolvidos: equipe, poder público, população. As estratégias adotadas mostraram-se efetivas no sentido de ampliar a participação dos munícipes, tendo sido deliberado pelas equipes a manutenção dos esforços de divulgação e mobilização ao longo de toda a Operação.

A experiência de coordenação das oficinas e palestras confirmou para os universitários a importância do planejamento e da clareza dos objetivos a se atingir como condição para implementar ações orientadas, organizadas, efetivas e eficazes. Planejamento e improviso, aspectos aparentemente contraditórios, revelaram-se opostos complementares no curso da ação. Senão, vejamos. Como regra, as condições reais com as quais os discentes se defrontaram no momento de implementação do planejado divergiam do esperado, exigindo capacidade de improviso. Não obstante, a improvisação incidia fundamentalmente sobre as estratégias, recursos e manejo do tempo, que poderiam ser circunstancialmente alterados sem prejuízo para a ação uma vez que os responsáveis pelas atividades detinham clareza dos objetivos a que se propunham com as oficinas e palestras voltadas a determinadas temáticas, clareza essa resultante do trabalho prévio de planejamento e que proporcionava, paradoxalmente, maior tranquilidade e liberdade de improviso. Assim, foi possível concluir que o trabalho de planejamento e a capacidade de improviso são ambos aspectos importantes na atuação profissional, desde que o planejamento seja o polo prevalente nessa relação.

\section{Fortalecimento das políticas sociais e acesso a direitos como eixos articuladores}

Como pode ser verificado na tabela 4 - que apresenta as ações realizadas em cada eixo, data, local e total de participantes - as oficinas, palestras e demais atividades distribuíram-se na zona urbana do município e em três distritos (Bauxi, Pindaival e Entre Rios), abrangendo temáticas relacionadas a: Saúde, Educação, Direitos Humanos e Cultura. De um modo geral, as oficinas e palestras tiveram bom andamento e foram bem avaliadas pelos participantes. Os objetivos do plano de trabalho foram atingidos, tendo sido criado um espaço de assimilação de novos conhecimentos e orientações, bem 
como discussão e compartilhamento dos problemas cotidianos, trocas de experiências e renovação da disposição para o enfrentamento dos desafios do trabalho e da luta do dia a dia.

No eixo Saúde, as atividades programadas com os agentes do Programa de Saúde da Família foram realizadas com sucesso e participação expressiva dos profissionais. Foi possível promover reflexões sobre o trabalho coletivo e fornecer orientações sobre o uso racional de medicamentos, o que se mostrou de grande relevância na avaliação dos agentes, uma vez que estes precisam orientar os usuários mesmo sem dispor de formação acadêmica para atuação em saúde. Houve grande apoio da Secretaria de Saúde para concretização das ações planejadas, tendo-se registrado apenas uma ação não efetivada: a palestra "Compreendendo e enfrentando o uso de álcool e outras drogas" não ocorreu por falta de público, embora tenha sido demandada pelo governo municipal durante a viagem precursora.

Além das atividades previamente programadas nesse eixo, foi incluída uma palestra para usuários idosos hipertensos e diabéticos - mediante articulação entre os eixos Saúde e Direitos Humanos que se concretizou pela parceria de trabalho de duas integrantes da equipe respectivamente das áreas de Farmácia e Serviço Social - a qual contou com ampla participação popular. As demais oficinas com idosos - vinculadas aos eixos Direitos Humanos e Cultura - atingiram plenamente os objetivos propostos, embora tenha sido registrada baixa participação em termos numéricos ${ }^{8}$. Os idosos mostraram-se receptivos a todas as atividades propostas, discutindo ativamente questões do envelhecimento e problemas enfrentados no cotidiano, com ênfase a relatos de violência patrimonial ${ }^{9}$; teve destaque nas atividades a participação ativa de idosos ligados a um coletivo organizado e atuante no município denominado "Grupo da Melhor Idade".

No eixo Educação, as atividades com professores das escolas municipais foram todas satisfatoriamente concretizadas, tanto na sede quanto nos Distritos. Houve dificuldade em mobilizar o público adolescente para a participação nas oficinas, o que

\footnotetext{
${ }^{8}$ Um dos determinantes para o baixo número de participantes parece ter sido o descumprimento de um acordo feito com a Prefeitura para disponibilização de transporte para os usuários: foi relatado pelos participantes e confirmado por representantes da Prefeitura que o ônibus não passou no horário e locais combinados em três das quatro ocasiões.

${ }^{9}$ A violência patrimonial é uma forma de violência doméstica e familiar que consta do artigo $7^{\circ}$ da Lei $n^{\circ}$ 11.340/2006 (lei Maria da Penha) conforme segue: “[...] violência patrimonial, entendida como qualquer conduta que configure retenção, subtração, destruição parcial ou total de seus objetos, instrumentos de trabalho, documentos pessoais, bens, valores e direitos ou recursos econômicos, incluindo os destinados a satisfazer suas necessidades." (BRASIL, 2006, p. 2).
} 
em parte se deve ao fato de que a Operação ocorreu em período de férias escolares; mesmo com baixa procura, foi possível realizar as oficinas de orientação sexual e profissional tanto na sede quanto nos Distritos de Bauxi e Pindaival. A reflexão sobre a condição do professor, as finalidades do ensino e o sentido do trabalho docente, bem como a instrumentalização para intervenções pedagógicas relacionadas a temas complexos como etnia, gênero e diversidade sexual podem ser destacados como os principais resultados das ações realizadas junto aos professores. As oficinas de orientação sexual com os adolescentes ampliaram o conhecimento destes sobre métodos contraceptivos e esclareceram dúvidas sobre questões diversas relacionadas à sexualidade. Esse mesmo público foi beneficiado pelas oficinas de orientação profissional que proporcionaram um espaço de discussão sobre a relação dos estudos com o futuro profissional dos adolescentes, as possibilidades de inserção no mundo do trabalho na região e sobre a importância de se construir um projeto de vida com sonhos, metas e desejos futuros. Vale ainda pontuar a participação expressiva e o envolvimento das crianças nas sessões de contação de histórias e atividades lúdicas, o que contribuiu decisivamente para a mobilização da população para participação nas demais atividades realizadas pela equipe. Mostraram-se recursos fundamentais para qualificar e potencializar essa estratégia (como ação educativa e não meramente recreativa) um acervo de livros infantis previamente selecionados pela equipe segundo critérios teórico-filosóficos e político-pedagógicos, bem como um repertório de parlendas e brincadeiras musicadas protagonizados pela aluna de Pedagogia que integrava a equipe.

Ilustrando as dificuldades mencionadas acerca da divulgação prévia das atividades, uma oficina dedicada à problemática da violência (sexual) contra a criança não foi realizada na data inicialmente agendada por ausência de público. Após um trabalho de articulação com a Secretaria da Assistência Social foi possível o reagendamento e realização da oficina, contando com a participação de servidores da Saúde e da Educação do município e conselheiros tutelares. Assim, foi possível alcançar o objetivo de instrumentalizar os profissionais e propiciar um momento de debate e articulação entre diferentes atores do Sistema de Garantia de Direitos da Criança e do Adolescente.

No eixo Cultura, a equipe recebeu intensivo apoio do Secretário de Cultura e da Fundação de Cultura, que prontamente colocaram-nos em contato com representantes da cultura local e agentes culturais da cidade, possibilitando o acesso a festividades e outras atividades culturais. Durante tais eventos, gravações e entrevistas foram 
realizadas com o objetivo de compor um vídeo retratando a realidade cultural local e seus agentes. Foi possível registrar, por exemplo, o Cururu, o Siriri e o processo de produção da Viola de Cocho.

Por fim, gostaríamos de dar relevo à oficina "Participação Social e Cidadania", realizada na Câmara Municipal, contando com ampla participação tanto de representantes do poder executivo (dentre os quais destacamos o Secretário de Governo e a Secretária Municipal de Educação) quanto de membros da Sociedade Civil. Foi distribuída uma cartilha contendo uma descrição de mecanismos de controle e participação cidadã na Administração Pública - incluindo o Portal da Transparência, a Lei de Diretrizes Orçamentárias, os Conselhos Municipais etc. - a qual havia sido previamente preparada pela acadêmica responsável pela coordenação da atividade. Optou-se por uma abordagem dialógica, de modo que a exposição dos conteúdos foi entrecortada pela participação dos presentes. A certa altura, o clima tornou-se bastante acalorado, com participação tanto de dissidentes como de apoiadores do Poder Executivo. Ocorre que a divulgação dessa atividade atraiu membros da sociedade civil que estavam sentindo-se assolados, sobretudo, pelo problema da falta de água, tema que se mostrou prioritário durante a discussão. Se por um lado a abordagem escolhida mostrou-se ousada, porque catártica, por outro, mostrou-se acertada, pois proporcionou uma janela comunicativa - mediada por um membro externo ao município - entre representantes do poder público e membros da sociedade local dispostos a externalizar suas insatisfações, sem a ocorrência de violência física. Ao final, os secretários presentes comprometeram-se a dar solução ao problema da água, enquanto a população local asseverou seu compromisso em acompanhar e cobrar daqueles a proclamada solução. Uma segunda oficina foi realizada no distrito de Entre Rios, tendo, no entanto, um caráter mais informativo e orientador, até porque o público era formado apenas de moradores locais.

Pode-se destacar como um resultado comum a todas as atividades realizadas, incluindo as oficinas de Participação Social e Cidadania, a percepção da necessidade por parte dos servidores do município, grupo da Melhor Idade e cidadãos em geral, de espaços de discussão e organização de ações coletivas tendo em vista o enfrentamento dos problemas sociais e demandas locais gerais e específicas. 
Tabela 4 - Ações realizadas no município de Rosário Oeste na Operação Bororos do Projeto RONDON

\begin{tabular}{|c|c|c|c|c|}
\hline $\operatorname{EIXO}(\mathbf{S})$ & AÇÃo & DAta(s) & LOCAL & PARTICIPANTES \\
\hline Saúde & Oficina com agentes de saúde: & $\begin{array}{c}14 \mathrm{e} \\
15 / 07 / 2015\end{array}$ & PSF II e III & 21 \\
\hline Saúde & $\begin{array}{l}\text { Participação em reunião do } \\
\text { Conselho Municipal de Saúde }\end{array}$ & $16 / 07 / 2015$ & - & - \\
\hline Saúde & $\begin{array}{l}\text { Palestra sobre o uso racional de } \\
\text { medicamentos para agentes do } \\
\text { Programa de Saúde da Família }\end{array}$ & 20/07/2015 & $\begin{array}{l}\text { E. E. Marechal } \\
\text { Rondon }\end{array}$ & 13 \\
\hline $\begin{array}{l}\text { Saúde/ Direitos } \\
\text { Humanos }\end{array}$ & $\begin{array}{l}\text { Palestra sobre envelhecimento } \\
\text { ativo e uso de medicamentos para } \\
\text { usuários idosos e hipertensos }\end{array}$ & $23 / 07 / 2015$ & Igreja São José & 64 \\
\hline $\begin{array}{l}\text { Direitos } \\
\text { Humanos }\end{array}$ & $\begin{array}{l}\text { Oficina "Envelhecimento ativo e } \\
\text { direitos dos idosos" }\end{array}$ & $\begin{array}{c}16 \mathrm{e} \\
17 / 07 / 2015\end{array}$ & $\begin{array}{l}\text { CRAS - sede } \\
\text { Passagem do } \\
\text { Chiqueiro }\end{array}$ & 7 \\
\hline $\begin{array}{l}\text { Cultura/ } \\
\text { Direitos } \\
\text { Humanos }\end{array}$ & $\begin{array}{l}\text { Oficina "Envelhecimento e } \\
\text { regionalidade" }\end{array}$ & 14 e $19 / 2015$ & $\begin{array}{c}\text { E. E. Artur Borges } \\
\text { Praça Central }\end{array}$ & 6 \\
\hline Educação & $\begin{array}{l}\text { Palestra e discussão sobre } \\
\text { "Desenvolvimento Humano e } \\
\text { educação" com profissionais da } \\
\text { educação }\end{array}$ & $15 / 07 / 2015$ & $\begin{array}{c}\text { E. E. Elizabeth } \\
\text { Evangelista Pereira }\end{array}$ & 17 \\
\hline Educação & $\begin{array}{l}\text { Oficina sobre Projeto Político } \\
\text { Pedagógico e o } \\
\text { sentido/significado do trabalho } \\
\text { docente }\end{array}$ & $17 / 07 / 2015$ & $\begin{array}{l}\text { E.E. Cel Artur } \\
\text { Borges }\end{array}$ & 19 \\
\hline $\begin{array}{l}\text { Educação/ } \\
\text { Direitos } \\
\text { Humanos }\end{array}$ & Infância, etnia e gênero & $\begin{array}{c}16 \text { e } \\
20 / 07 / 2015\end{array}$ & $\begin{array}{l}\text { Distrito de Bauxi } \\
\text { E.E. Marechal } \\
\text { Rondon }\end{array}$ & 37 \\
\hline $\begin{array}{l}\text { Educação/ } \\
\text { Direitos } \\
\text { Humanos }\end{array}$ & Educação sexual e diversidade & $\begin{array}{c}22 \mathrm{e} \\
23 / 07 / 2015\end{array}$ & $\begin{array}{c}\text { Distrito de } \\
\text { Pindaival } \\
\text { E. E. Elizabeth } \\
\text { Evangelista Pereira }\end{array}$ & 20 \\
\hline Educação & $\begin{array}{l}\text { Oficina de literatura infantil para } \\
\text { professores }\end{array}$ & $23 / 07 / 2015$ & $\begin{array}{c}\text { E. E. Elizabeth } \\
\text { Evangelista Pereira }\end{array}$ & 14 \\
\hline Educação & $\begin{array}{c}\text { Orientação profissional para } \\
\text { adolescentes }\end{array}$ & $\begin{array}{c}22 \mathrm{e} \\
23 / 07 / 2015\end{array}$ & $\begin{array}{c}\text { E. E. Coronel Artur } \\
\text { Borges } \\
\text { Distrito de } \\
\text { Pindaival }\end{array}$ & 6 \\
\hline Educação & $\begin{array}{c}\text { Prevenção às DSTs e gravidez na } \\
\text { adolescência }\end{array}$ & $\begin{array}{c}16,20 \mathrm{e} \\
22 / 07 / 2015\end{array}$ & $\begin{array}{l}\text { E. E. Marechal } \\
\text { Rondon }\end{array}$ & 19 \\
\hline
\end{tabular}




\begin{tabular}{|c|c|c|c|c|}
\hline & & & $\begin{array}{l}\text { Distrito de Bauxi } \\
\text { Distrito de } \\
\text { Pindaival }\end{array}$ & \\
\hline $\begin{array}{l}\text { Cidadania e } \\
\text { participação } \\
\text { popular }\end{array}$ & $\begin{array}{l}\text { Palestra e discussão sobre } \\
\text { "Participação social e cidadania" }\end{array}$ & $\begin{array}{c}17 \mathrm{e} \\
22 / 07 / 2015\end{array}$ & $\begin{array}{l}\text { Câmara Municipal } \\
\text { Distrito de } \\
\text { Pindaival }\end{array}$ & 55 \\
\hline Cultura & $\begin{array}{l}\text { Cine-Rondon - Mini-ciclo de } \\
\text { Cinema Nacional }\end{array}$ & $\begin{array}{c}13,15 \mathrm{e} \\
21 / 07 / 2015\end{array}$ & $\begin{array}{c}\text { Cinema Municipal } \\
\text { Distrito de Bauxi }\end{array}$ & 28 \\
\hline Cultura & Cine-Rondon Infantil & $\begin{array}{l}16,18,21 \mathrm{e} \\
22 / 07 / 2015\end{array}$ & $\begin{array}{c}\text { Cinema Municipal } \\
\text { Distrito de Bauxi } \\
\text { Distrito de } \\
\text { Pindaival }\end{array}$ & 26 crianças \\
\hline $\begin{array}{c}\text { Educação/ } \\
\text { Cultura }\end{array}$ & $\begin{array}{l}\text { Contação de histórias e atividades } \\
\text { lúdicas para crianças }\end{array}$ & $\begin{array}{l}13,16,21 \\
22 \mathrm{e} \\
24 / 07 / 2015\end{array}$ & $\begin{array}{c}\text { Praça Central } \\
\text { Distrito de Bauxi } \\
\text { Passagem do } \\
\text { Chiqueiro } \\
\text { Distrito de Entre } \\
\text { Rios } \\
\text { Distrito de } \\
\text { Pindaival }\end{array}$ & 65 crianças \\
\hline $\begin{array}{c}\text { Direitos } \\
\text { Humanos }\end{array}$ & $\begin{array}{c}\text { Marcas invisíveis da violência: } \\
\text { possibilidades de enfrentamento } \\
\text { na infância }\end{array}$ & $21 / 07 / 2015$ & Patotinha & 18 \\
\hline $\begin{array}{l}\text { Direitos } \\
\text { Humanos }\end{array}$ & $\begin{array}{l}\text { Oficina "Não se nasce mulher, } \\
\text { torna-se mulher" }\end{array}$ & $14 / 07 / 2015$ & E. E. Arthur Borges & 7 \\
\hline $\begin{array}{l}\text { Direitos } \\
\text { Humanos }\end{array}$ & $\begin{array}{l}\text { Grupo de mulheres: vida, família } \\
\text { e violência }\end{array}$ & $20 / 07 / 2015$ & $\begin{array}{l}\text { Distrito de Entre } \\
\quad \text { Rios }\end{array}$ & 6 \\
\hline \multirow[t]{2}{*}{ Cultura } & $\begin{array}{l}\text { Visitas, entrevistas e participação } \\
\text { em festividades locais para } \\
\text { registro e produção de curta- } \\
\text { metragem }\end{array}$ & & & - \\
\hline & & & & 448 \\
\hline
\end{tabular}

Fonte: Martins et al. (2015).

O encontro e o diálogo com a população e com os profissionais do município proporcionado pelas oficinas e palestras, bem como a convivência com os moradores ao longo das duas semanas que a equipe permaneceu em Rosário Oeste, permitiram identificar algumas problemáticas do território que necessitam de intervenção e providências do Poder Público. No último dia da Operação, foi solicitada uma audiência com o prefeito e secretários de governo para entrega de relatório final - contendo 
registro e sistematização das atividades realizadas no período e devolutiva para a prefeitura acerca das demandas e necessidades identificadas pela equipe no município bem como objetivando um espaço de avaliação do trabalho realizado por parte dos gestores do município. Reproduzimos a seguir trecho do relatório que contém essa devolutiva:

Considerando o compromisso desta equipe em contribuir com a Gestão tendo em vista ampliar o bem-estar social da comunidade local, indicamos abaixo algumas das constatações para averiguação, avaliação e intervenções desta Prefeitura:

1. Abastecimento de água: Foi relatado à equipe, recorrentemente, a falta de água no município, o que configura um problema de extrema gravidade, com implicações para o cotidiano e a saúde da comunidade. Para além dos relatos, pudemos vivenciar o drama da população, uma vez que durante nossa estadia o fornecimento de água cessava quase todos os dias no alojamento.

2. Ausência de transporte público: Os rondonistas ouviram relatos e testemunharam a dificuldade de deslocamento da população, especialmente da população idosa e da zona rural, levando ao questionamento sobre a necessidade de transporte público no município.

3. Sobrecarga de trabalho para a equipe técnica do CRAS: O volume de trabalho e a diversidade de tarefas sob responsabilidade da equipe técnica do CRAS (Centro de Referência da Assistência Social) podem ser considerados excessivos e extrapolam a especificidade do órgão em questão. Isso gera sobrecarga de trabalho e risco de adoecimento físico e psíquico por condições laborais. Além disso, as problemáticas que clamam o serviço da assistência social do município superam as possibilidades de atendimento do CRAS, havendo demanda para a criação do CREAS (Centro de Referência Especializada em Assistência Social) e/ou a ampliação do quadro de funcionários do órgão existente.

4. Demanda por atendimento psicossocial a usuários de drogas lícitas e ilícitas e pessoas em sofrimento mental: Em reuniões com a Secretária de Saúde, equipe técnica do NASF (Núcleo de Assistência à Família) e membros do Conselho Municipal de Saúde, foi identificado que não existem no município serviços públicos especializados para atender indivíduos (e familiares) em sofrimento mental e situações de abuso de álcool e outras drogas. Frente aos parâmetros e exigências legais para criação de um CAPS (Centro de Assistência Psicossocial) no município, pode-se considerar a hipótese de Consórcio Intermunicipal. Isso atenderia a grande parte da demanda, mas idealmente o atendimento a casos específicos dos usuários de drogas lícitas e ilícitas requereria a implantação de um serviço especializado orientado pela perspectiva da redução de danos, defendida pela Organização das Nações Unidas como a abordagem mais efetiva para o enfrentamento dessa problemática social.

5. Distribuição de medicamentos essenciais: Os munícipes e agentes de saúde relataram a falta de acesso a medicamentos básicos (ex: anti-hipertensivos, anti-diabéticos). Parece haver falhas no processo de comunicação que se inicia com as demandas dos usuários 
e tem término no processo de aquisição dos medicamentos. Os próprios ACSs (Agentes Comunitários de Saúde) desconhecem os trâmites desse processo.

6. Insegurança dos pedestres, ciclistas e motoristas: Chamou a atenção a precariedade das vias de circulação em algumas regiões do município, destacando-se a ausência de calçamento e iluminação adequados e de ciclovias, que seriam imprescindíveis considerando que grande parte da população utiliza a bicicleta como meio de transporte. No deslocamento para as atividades na zona rural passamos por pontes que não oferecem condições para a travessia segura dos pedestres e pudemos vivenciar a dificuldade dos moradores dessa região para acessar a sede do município. Foi impactante para a equipe a notícia do falecimento do Sr. Aluísio, no dia 18 de julho (um dia após ele ter sido entrevistado pelo grupo, como parte das atividades do eixo cultural), em um atropelamento na BR justamente em um trecho que não oferece segurança para travessia dos pedestres e ciclistas. (MARTINS et al., 2015).

O conteúdo do relatório foi discutido coletivamente nas reuniões da equipe; sua redação teve como base os relatórios de cada ação que foram solicitados aos estudantes ao longo da Operação. Em nossa avaliação, a elaboração coletiva do relatório foi uma estratégia positiva que permitiu ao grupo dimensionar os resultados alcançados e ponderar os erros e acertos da intervenção. Além disso, canalizou as angústias vivenciadas ao longo das duas semanas no contato humano direto com a população, marcado pela sistemática constatação da violação de direitos típica da vida nas periferias brasileiras, dando conhecimento dos fatos ao poder público, com sentido de denúncia e cobrança de providências e ao mesmo tempo de contribuição para a gestão e para o bem-estar da comunidade. A participação dos acadêmicos na audiência com o prefeito e secretários municipais acompanhando os docentes coordenadores pode ser considerada ponto alto do trabalho realizado, colocando frente a frente gestores e estudantes universitários em torno de debates sobre necessidades da população e garantia de direitos.

Com esse relato analítico-sintético das ações realizadas, pode-se compreender que o fortalecimento das políticas sociais e a perspectiva de acesso a direitos foram os eixos articuladores de nosso trabalho, que buscou: municiar a população local em termos de conhecimentos sobre meios de acesso/garantia de direitos; instrumentalizar agentes públicos que atuam nas políticas sociais de Saúde, Educação, Direitos Humanos e Cultura; sensibilizar o estudante universitário para a importância e o sentido das políticas sociais a partir do contato com os dramas concretos da população local. 


\section{O processo grupal e a experiência de coordenação da equipe}

Como docentes do ensino superior, consideramos que a coordenação de equipe do Projeto Rondon representou oportunidade ímpar de desenvolvimento profissional e avaliamos que o processo de grupalização vivenciado pelos acadêmicos foi um determinante fundamental para o caráter formativo da experiência.

Desposamos uma concepção democrática e participativa de gestão, ao mesmo tempo em que identificamos o professor como profissional que detém conhecimento e capacidades ainda em formação no aluno, o que lhe imputa a responsabilidade de dirigir o processo educativo e lhe confere autoridade pedagógica (que não se confunde com autoritarismo). Adotamos, assim, um modelo de coordenação de grupo baseado em processos decisórios compartilhados, comunicações livres, tratamento igualitário, condução transparente do trabalho e autonomia de ação ${ }^{10}$.

Avaliamos como extremamente positivo o processo de grupalização que vivenciamos com os alunos, que foi marcado pela predominância de relações cooperativas e solidárias, senso de companheirismo e genuínas trocas afetivas. A formação acadêmica e pessoal prévia de cada integrante é certamente fator importante para que um agrupamento venha a se constituir, de fato, como grupo, mas o determinante prevalente é a natureza das relações que se estabelecem. Em nossa equipe, as interações estabelecidas constituíram base para relações que evoluíram para a formação de vínculos, pautados tanto nas relações funcionais (referentes ao âmbito do trabalho) quanto primárias (referentes ao âmbito da afetividade) (MARTIN-BARÓ, 2004).

Alguns aspectos desse processo de grupalização merecem destaque. Os encontros de preparação que precederam o início da Operação e as estratégias então utilizadas - que criaram a condição de interdependência nas tarefas - colaboraram para a emergência do sentimento de "nós" já na fase anterior à ida ao município. Durante a Operação, em virtude de cada município receber duas equipes que compartilham alojamento, transporte e eventualmente ações em parceria, cria-se uma condição de integração e ao mesmo tempo diferenciação ("nossa equipe"), importante para o

${ }^{10}$ A dose de autonomia concedida aos acadêmicos se mostrou um problema (no sentido filosófico do termo). Finda a experiência, avaliamos que em determinadas situações foi concedida autonomia em excesso, o que concorreu para a não conclusão de tarefas importantes e previamente combinadas, como a produção de um curta-metragem abordando as riquezas culturais e ecológicas do município. Por outro lado, a autonomia na condução das ações e a relativa autonomia no manejo do tempo enquanto permaneciam no alojamento (condicionadas ao cumprimento de responsabilidades assumidas e acordadas no coletivo), colaboraram para fomentar nos universitários o senso de responsabilidade profissional. 
desenvolvimento da identidade grupal. Também colaborou decisivamente para a consolidação da identidade grupal e vinculação entre os membros a possibilidade de compartilhar momentos de descontração e a opção pelo enfrentamento fraterno e dialogado de tensões e conflitos (ao invés de sua ocultação e esquiva). Foi evidente, no curso da experiência, que os coordenadores funcionaram como modelos que passaram a regular as interações e relações em construção no interior do grupo, em especial na fase inicial do processo, e que sua intervenção mediadora foi fundamental para a vivência de um processo grupal saudável e formativo, o que indica a importância de se estabelecer princípios e parâmetros para o manejo da grupalidade em situações de formação profissional pautadas no trabalho extensionista coletivo interdisplinar.

\section{Contribuições para a formação do universitário: compromisso social do profissional}

Em ensaio filosófico que discute o compromisso do profissional com a sociedade, Paulo Freire (1981, p.9) assevera que “[...] o compromisso, próprio da existência humana, só existe no engajamento com a realidade, de cujas águas os homens verdadeiramente comprometidos ficam 'molhados', ensopados." O compromisso é, para o educador, um quefazer radical, concreto e totalizante (que implica a totalidade do ser). Tendo em vista o exposto nesse artigo, consideramos que a experiência de participação no Projeto Rondon proporcionou aos discentes de nossa equipe esse mergulho na realidade fomentador de uma atitude de comprometimento com os problemas enfrentados cotidianamente com a população e de busca em contribuir para sua superação a partir do específico lugar de futuros profissionais atuantes na sociedade brasileira. Os principais determinantes para que a experiência tenha tido esse caráter foram, em nossa avaliação: a opção pelo fortalecimento das políticas sociais e perspectiva de acesso a direitos como articuladores fundamentais da intervenção contribuindo para afastar o trabalho do caráter assistencialista e paternalista ainda bastante arraigado na "mentalidade rondonista"; e a experiência de grupalização e trabalho coletivo.

Freire (1981, p.7) indica que a primeira condição para que um ser possa assumir um ato comprometido está em ser capaz de agir e refletir: “é preciso que seja capaz de, estando no mundo, saber-se nele”. A intervenção na realidade do município por meio das oficinas e palestras e as reuniões coletivas realizadas quase diariamente para compartilhamento e avaliação do trabalho realizado (incluindo não apenas estratégias 
bem ou mal sucedidas e resultados alcançados ou não, mas também angústias e dificuldades vivenciadas) proporcionaram uma relação consciente e refletida com a própria atuação extensionista e os impactos gerados pela intervenção na realidade, provocando, em última instância, a tomada de consciência sobre o 'estar no mundo' na condição de futuro profissional.

PROFESSIONAL COMMITMENT TO SOCIETY: A REPORT OF A SOCIAL INTERVENTION BY ACADEMICS IN A BRAZILIAN SMALL TOWN

\begin{abstract}
This paper aims to report the experience of a group composed by two assistant professors and eight students from UNESP in a multidisciplinary social project, realized in July, 2015 in a small town from Mato Grosso State. The team was formed by students from the following areas: public management, biology, pharmacy, education, psychology, and social service. We are going to describe here the process of preparation, planning and execution of the actions developed by the team, stressing the main results, the difficulties faced by the students, and how this experience has added to them in terms of their professional improvement. Two aspects will be highlighted as primary in the achievement of our goals: the group process and social policies as guiding principles of the actions developed.
\end{abstract}

Key words: Social project. Skill building. Group process. Social policies. Projeto Rondon.

\title{
REFERÊNCIAS
}

ATLAS do Desenvolvimento Humano no Brasil. Mato Grosso. [S.1.]: PNDU, 2013a. Disponível em: <http://www.atlasbrasil.org.br/2013/pt/perfil_uf/mato-grosso>. Acesso em: 23 jun. 2016.

ATLAS do Desenvolvimento Humano no Brasil. Rosário Oeste. [S.l.]: PNDU, 2013b. Disponível em: http://www.atlasbrasil.org.br/2013/pt/perfil_m/rosariooeste_mt\#caracterizacao. Acesso em: 23 jun. 2016.

BRASIL. Portaria normativa $\mathrm{n}^{\circ} 2.617$ /MD, de 7 de dezembro de 2015. Aprova a concepção política do Projeto Rondon. Diário Oficial [da] União, Brasilia, 8 dez. 2015a. Seção 1, p. 35. Disponível em:

<http://www.lex.com.br/legis_27049227_PORTARIA_NORMATIVA_N_2617_DE_7 _DE_DEZEMBRO_DE_2015.aspx>. Acesso em: 23 jun. 2016.

BRASIL. Ministério da Agricultura. Mato Grosso lidera ranking nacional do valor bruto da produção. Notícias, Brasília, 16 set. 2015b. Disponível em: 
<http://www.agricultura.gov.br/comunicacao/noticias/2015/09/mato-grosso-lideraranking-nacional-do-valor-bruto-da-producao>. Acesso em: 24 jun. 2016.

BRASIL. Lei ${ }^{\circ} 11.340$, de 7 de agosto de 2006. Cria mecanismos para coibir a violência doméstica e familiar contra a mulher, nos termos do § 80 do art. 226 da Constituição Federal, da convenção sobre a eliminação de todas as formas de discriminação contra as mulheres e da Convenção Interamericana para prevenir, punir e erradicar a violência contra a mulher; dispõe sobre a criação dos juizados de violência doméstica e familiar contra a mulher; altera o Código de Processo Penal, o Código Penal e a Lei de Execução Penal; e dá outras providências. Diário Oficial [da] União, Brasília, 8 ago. 2006. Disponível em: <https://www.planalto.gov.br/ccivil_03/_Ato2004-2006/2006/Lei/L11340.htm>. Acesso em: 23 jun. 2016.

CARDOSO, R. Em 2005, o velho Projeto Rondon. O Estado de São Paulo, São Paulo, 30 jan. 2005. Espaço Aberto, p. A2,. Disponível em:

<http://pib.socioambiental.org/en/noticias?id=33652>. Acesso em: 23 jun. 2016.

FREIRE, P. Compromisso do profissional com a sociedade. In: FREIRE, P. Educação e mudança. 12. ed. Rio de Janeiro: Paz e Terra, 1981. p.7-13.

\section{INSTITUTO BRASILEIRO DE GEOGRAFIA E ESTATÍSTICA [IBGE]. Mato}

Grosso: Rosário Oeste: histórico. Rio de Janeiro, [2015]. Disponível em: $<$ http://cidades.ibge.gov.br/painel/historico.php?lang=\&codmun=510770\&search=mato -grosso|rosario-oeste|infograficos:-historico>. Acesso em: 23 jun. 2016.

MARTIN-BARÒ, I. Sistema, grupo y poder. San Salvador: UCA, 2004.

\section{MARTINS, F. R. et al. Relatório final e devolutiva para a Prefeitura do Município} de Rosário Oeste. Rosário Oeste, jul. 2015. 7 p.

SENHORAS, E. M. Políticas públicas nos anos noventa: um ensaio sobre as causas e implicações da crise do Estado brasileiro de Bem Estar Social. Revista Oikos, [Rio de Janeiro], v. 2, n. 2, p. 2-20, jan. 2003. 